\title{
Supervision Mechanism for Environmental Law Enforcement in China
}

\author{
Guilin Gao \\ Capital University of Economics and Business \\ Beijing, China \\ gaoguilinrenda@163.com
}

\author{
Zhengjia Fu \\ Capital University of Economics and Business \\ Beijing, China \\ 441586900@qq.com
}

\begin{abstract}
China's environmental law enforcement is in the perfect order. A special supervision mechanism is developed accordingly. Theory and effect of environmental law enforcement supervision require urgent analysis and reflections. In 2010, Supervision Measures after Administrative Enforcement of Environmental Laws were issued. In 2016, the first Central Environmental Protection Supervision Team was founded, symbolizing the perfecting process of China's environmental law enforcement supervision mechanism. In this study, specific theoretical connotation of China's environmental law enforcement supervision was analyzed. Differences of supervision from monitoring and inspection were illustrated. On this basis, effect and shortcomings of law enforcement supervision were analyzed and corresponding improvement suggestions were proposed, including perfecting the mechanism, reducing rights of regional enforcement supervision and accelerating institutionalization. Finally, it comes to conclusions. It accepts the establishment and development of China's environmental law enforcement supervision system, puts forward countermeasures against shortcomings, and evaluates the environmental law enforcement supervision system comprehensively.
\end{abstract}

Keywords-environmental law enforcement supervision; environmental law enforcement; central environmental protection supervision team; environmental protection departments

\section{THEORIES}

A. Concepts and theoretical annotations of environmental law enforcement and environmental law enforcement supervision

Environmental law enforcement, or known as environmental administrative law enforcement, refers to major means of environmental management. Environmental administrative law enforcement means that the administrative subject adopts environmental administration behaviors that will influence rights and obligations of the administrative counterpart according to applicable laws.

Environmental law enforcement supervision is one supervision mechanism on environmental administrative law enforcement[1]. Specifically, it is the generic term that legal institutions of People's Government of the same level, superior environmental administrative subject and legal institutions of environmental administrative subject supervise and check legality and appropriateness of national administrative agencies' and officials' administrative enforcement of laws as well as adopt essential measures to correct them.

With respect to environmental law enforcement supervision, we are necessary to distinguish monitoring, inspection and supervision.

Relatively, monitoring is a larger concept and covers extensive subjects, including state organs, social groups, political parties and citizens. The later one only involves state organs. Indeed, monitoring by state organs is an important mean of China's environmental law enforcement supervision for the moment and plays the crucial role. However, it is undeniable that social groups and citizens are playing indispensable roles. Therefore, monitoring is a more macroscopic concept and is one term of examination which is used mostly in practical life.

Supervision is more specific than monitoring. Both are official terms. Since their administrative behaviors are carrying with authority, the coercive force and efficiency are undoubtedly higher. For supervision and monitoring, supervision is a long-term behavior and monitoring is a discontinuous behavior. Besides, supervision has stricter systematicness and explicit layering and division of functions in the organization. Finally, supervision owns higher effectiveness due to the long-term behavior and strict systematicness.

Although inspection has certain authority, it is more like a work summary and tends to discover problems. However, different from inspection, supervision is stricter and thereby possesses stronger punishment. Additionally, the foundation of the central environmental protection supervision team endows supervision another attribute, which is recognized as inner-party supervision.

\section{B. Theories of environmental law enforcement supervision}

The environmental law enforcement supervision involves extensive subjects, including Ministry of Environmental Protection, local environmental protection department, local government and other departments authorized by laws and regulations[2]. It is such extensive range of subjects that determines and requires coordination and cooperation of involved departments. Specifically, subjects of environmental law enforcement supervision include: 
- Ministry of Environmental Protection. It is a department of the State Council founded in 2008 and is held responsible for drafting and implementation of environmental protection plans, policies and standards, organization of environmental functional district planning, supervision of environmental pollution management, coordination and solving key environmental protection problems. Another important duty of the Ministry of Environmental Protection is to formulate and implement environmental policies as well as supervise and execute laws. These reflect that supervision of the Ministry of Environmental Protection is a global one and supervise enforcements of environmental protection laws in different departments. Since legal supervision covers supervision of law enforcement, the Ministry of Environmental Protection also can supervise specific administrative behaviors that environmental protection departments at all levels adopted according to laws.

- Superiors of local environmental protection departments: environmental protection departments of county-level or higher Local People's Government can execute environmental laws. The corresponding superiors shall make top-down supervision on specific administrative measures and give corresponding countermeasures to problems.

- Specific supervision organizations: Founded in 2016, the Central Environmental Protection Supervision Team is to improve environmental protection responsibilities of local Party committee, reinforce implementation of ecological civilization construction and green development in local government, and fulfill Party-Political joint responsibility and "Two Duties for One Post". The environmental protection is ascended to the level of Party committee. This demonstrates that local Party committees and governments are supervised together and the supervision object is extended from "enterprise” to "politics”. With political supervision, the Central Environmental Protection Supervision Team is not only endowed with higher authority and is led by the central government, but also can guarantee transparency of political supervision. These explain why the team is named as Central Environmental Protection Supervision Team[3].

Supervision contents involve a large range and will be further enriched with the reinforcement of authority and institutionalism[4]. Currently, supervision contents can be divided into:

- Legality of supervision entity. Since administrative enforcement of environmental laws is often a punitive behavior, it has to examine where there are laws to abide by firstly, other it might be viewed beyond the legal authority.

- Legality of supervision program. A society ruled of law pursues both substantive justice and procedural justice. The later one can ensure justice of results and convince objects of law enforcement, thus generating government credibility. Therefore, attentions shall be paid to the consistence of administrative behaviors with legal procedures

- Sufficiency of evidence. Administrative enforcement of environmental laws shall be based on facts and follow the rule of "collecting evidence first and making judgment second”.

- Reasonability of supervision behavior. With the premise of "legality of environmental administrative behaviors", execution of free discretion is another important supervision content, which requires us to judge reasonability of our judgment.

- Law enforcement officers. This is the responsibility of the Central Environmental Protection Supervision Team. Malpractice and improper enforcement are often related with person instead of things. If denial of justice can be corrected, poor ideology of environmental law enforcement officers is the priority among priorities.

According to the Article 13 of Supervision Measures after Administrative Enforcement of Environmental Laws issued by the Ministry of Environmental Protection, the ultimate remedy of enforcement supervision involves subjects of administrative law enforcement. It "regulates inferior environmental protection departments of People's Government to give punishment or treatment according to laws. The superior environmental protection departments of People's Government can report feedback to related local People's Government or investigate with disciplinary inspection department and affix the administrative responsibility for related person”. This article determines supervision on law enforcement officers, but still has some shortcomings. The most important shortcoming lies in the over simplicity of the article and ambiguous determination on responsibility degree. This is why the Central Environmental Protection Supervision Team is useful under current serious environmental protection. More details will be discussed in the following text.

\section{CURRENT SituAtions}

\section{A. Development achievement}

Supervision Measures after Administrative Enforcement of Environmental Laws issued by the Ministry of Environmental Protection institutionalized the supervision after administrative law enforcement in official document in 2010. On July, 2016, the first Central Environmental Protection Supervision Team was founded and stationed in 8 provinces and municipalities to supervise environmental law enforcement. So far, two supervision tasks have been achieved significant fruits. It increases environmental protection responsibility of local governments, solves abundant environmental issues, and promotes construction of long-term mechanisms for local environmental protection. Different from previous monitoring and supervision subjects, the Central Environmental Protection Supervision Team has two obvious characteristics. Firstly, it supervises both "politics and people". It not only supervises environmental law enforcement, but also justice of 
law enforcement officers, which can ensure careful behavior and dual responsibility of law enforcement officers and prevent benefit exchange with pollution enterprises. Secondly, it enhances Party committee's sense of duty in local environmental protection. In the past, environmental protection was led by the government and the governmental environmental protection departments execute related laws and make self-supervision. Now, local Party committee is enlisted into the supervision range. Party committee pays attentions to environmental protection, which is beneficial for local environmental protection to attract more attentions and reduce environmental pollution tolerance of local supporting enterprises.

\section{B. Scattered subjects of law enforcement lead to low efficiency of multi-point supervisions}

Environmental problem is a complicated system engineering project and involves coordination of multiple departments. China's environmental law enforcement composed of "leadership of competent departments and assistance of functional department" brings many environmental law enforcement departments. Moreover, there are conflicts of interest and crossing of functions among environmental authorities. Buck-passing may occur with considerations to benefits of departments. Furthermore, law enforcement efficiency is low because of complicated division of functions and powers.

Take atmospheric pollution control for example. For the same atmospheric pollution caused by open-air barbecue, the blocking wall involves many administrative departments. Open-air barbecue in yard is subjected to environmental protection departments, but the open-air barbecue in roadside market is controlled by urban management department. Atmospheric pollution caused by industrial and agricultural production is in the charge of environmental protection departments, but raise dust in the construction site is in the charge of construction committee. Atmospheric pollution caused by motor vehicle is controlled by either environmental protection departments or public security departments. On the one hand, such scattered subjects of law enforcement lead to low efficiency of multi-point supervisions cause low administration efficiency and weaken law enforcement efforts. On the other hand, it increases supervision cost. Different administrative departments are supervised by superior administrative departments and corresponding environmental law enforcements are supervised by superiors, thus forming the situation of multi-point supervision and low supervision efficiency[5].

\section{Obstacles against cooperation of Beijing, Tianjin and Hebei provinces in boundary and transboundary law enforcement supervision}

Environmental problem is a regional problem. Natural mountains and rivers, especially atmospheric motion, present regional characteristics and wouldn't be cut by administrative division. Therefore, environmental law enforcement protection shall enhance regional cooperation. During the BeijingTianjin-Hebei integration, socioeconomic integration lays a good foundation for integration of environmental protection.
At present, there are many cooperation obstacles, thus overlooking and delaying treatment of boundary and transboundary environmental problems. Environmental pollution management is restricted by administrative division, failing to achieve expected efficiency and result.

Viewed from environmental law enforcement, capital, municipalities and cities have significantly different concepts and management modes as well as conservative considerations to self-protection and self-development. No consensus on compensation of water pollution and coordination of transboundary pollution has been reached yet. There are overlooking on boundary environmental problems in Beijing, Tianjin and Hebei and poor coordination of transboundary environmental problems. With respect to haze control, different regions make independent total pollution control goals, without considerations to overall economic development and environmental carrying capacity of the Beijing-Tianjin-Hebei region. Heavy pollution enterprises are moved to Hebei Province to relieve environmental pressure in Beijing. In this way, law enforcement deviates from the idea of integral region.

From the perspective of law enforcement supervision, supervisions are performed independently from the capital to municipality and then to cities. Such mismatching of administrative levels will cause "mandatory" supervision cooperation. If using commands of local government agencies and central government as the guideline, environmental protection doesn't participate in cooperation actively and return to the origin of appealing by Beijing and executing by Tianjin and Hebei. Meanwhile, high administrative level is difficult to get contact with law enforcement, thus causing poor supervision on the most basic and universal environmental law enforcement departments.

\section{Concern on "campaign-style" law enforcement and "campaign-style" supervision}

In the past, there's no special supervision organization and the National People's Congress was held responsible to environmental law enforcement supervision. Abundant manpower and material resources were input for centralized investigation. Nevertheless, such supervision lacked an effective coping mechanism to changing environmental problems. Supervision of superior environmental protection departments has strong temporary characteristics. Annual routine examination is more like an annual report that summarizes experiences and shortages of inferior environmental protection departments, but fails to realize the supervision goal. These shortages are the consequence of high mobility and discontinuity of these supervisions.

Undoubtedly, the pilot work of Central Environmental Protection Supervision Team has achieved outstanding fruits. For example, the $17^{\text {th }}$ supervision team of Ministry of Environmental Protection entered in Jiaozuo on February $15^{\text {th }}$, 2017 and submitted 125 environmental problems and solved 88 problems in one-month atmosphere quality supervision. However, it is widely concerned for subsequent environmental management in old pilots after the supervision team moves to new pilots. Jining Chen, director of Ministry of Environmental 
Protection, announced on the press conference that "we are discussing whether it is necessary to formulate Regulations on Environmental Protection Supervision and ascend it to the institutional level.” Whether long institutionalization can meet current requirements on timeliness and long-term efficiency of environmental protection supervision have to be investigated continuously in practices [6].

\section{SugGestions AND MEASURES}

\section{A. Perfect supervision system}

A uniform environmental law enforcement supervision department shall be set up and authorities of the supervision department shall be expanded in order to perfect the supervision system.

It is easy to discover from American supervision system that under the federal system, the National Environment Protection Bureau is the major supervision organization in the United States, assisted by Ministry of the Interior and Ministry of Agriculture. However, these three organizations are subordinated to the president directly and enjoy highly independence. In environmental law enforcement supervision system, they possess the supreme supervision authority of the administrative system. The dominant role of the supreme supervision organizations is extremely stable no matter how complicated and large quantity of subordinated agencies. In practical supervision activities, coordination of agencies is under the control of the Ministry of Environmental Protection.

Therefore, China shall build a highly independent environmental law enforcement supervision department with more authorities to improve efficiency and institutionalization.

\section{B. Reduce rights of local enforcement supervision and make joint enforcement supervision}

Regional division for environmental law enforcement in China is very prominent. Poor regional communication makes joint environmental law enforcement difficult. Similarly, supervision in relative to specific law enforcement content is restricted by division of regional powers. Except for the construction of uniform supervision subject, attentions also shall be paid to eliminate regional estrangement and make joint law enforcement supervision.

Specifically, regional environmental law enforcement supervision departments shall make joint activities. For example, haze control in Beijing and Hebei Province are not very optimistic. Nevertheless, Beijing enjoys better conceptual and technological supports and shall drive Hebei supervision organization to make joint supervision activities and eliminate mutual divergences. The complicated haze control in cities and districts of Hebei Province will accumulate more experiences. Based on continuous supervision cooperation and sharing of concepts and experiences, Beijing and Hebei Province will realize the win-win goal[7].

\section{Accelerate institutionalization of environmental law enforcement supervision}

On the Fifth Session of the 12th NPC which was held on March 9th, Jining Chen, mentioned whether supervision shall be ascended to the institutional level of Regulations on Environmental Protection Supervision, indicating that China's institutionalization of law enforcement supervision is developing orderly. However, attentions shall be paid to that legislation hysteresis is difficult to cope with changing environmental law enforcement situations.

Therefore, if neglecting legislation hysteresis, procedures of environmental law enforcement supervision can be determined preliminarily by specific regulations, administrative rules and local administrative laws and regulations before the issuing of official legislation document. Details and subsequent remedy and punishment measures shall be introduced in these documents. Combining with timeliness documents to cope with changing environmental law enforcement, China's environmental law enforcement supervision can achieve outstanding effect in a short period. Next, the legislation shall be conducted based on summary and analysis of a certain period, finally establishing a perfect environmental law enforcement supervision system.

\section{CONCLUSION}

The establishment and perfection of China's environmental law enforcement supervision mechanism are not only a long-term effective environmental protection mechanism, but also can reflect the self-review to some extent due to the "people supervision", thus forcing subjects of law enforcement more cautious. However, the environmental law enforcement is encountered with several noticeable problems: difficult supervision caused by scattered executors, difficult regional cooperation in enforcement supervision, and inevitable "moving" supervision. To cope with existing or potential problems, an independent law enforcement supervision department shall be set up, which is conducive to increase centralization of authority. Moreover, it is suggested to reduce rights of local law enforcement supervision, but enhance collaborative law enforcement. Based on tremendous summarizations and practices, the environmental law enforcement supervision system is set up and fixed legal documents are formulated to prevent shortages of temporary policies.

\section{REFERENCES}

[1] Guangzhong Yang, Jinying Hu, Lei Zhao and Mo Wang, “Discussion on China's supervision system after administrative enforcement of environmental laws," China Science and Technology Information, 2012(In Chinese).

[2] Yongsheng Liu and Shengjun Ji, "Reflection on construction of China's supervision mechanism after basic environmental law enforcement," Environmental Science Survey, vol.5, 2013(In Chinese).

[3] Yan Lan, "Practice experiences of American's environmental law enforcement and enlightenment to China," NVIRONMENTAL PROTECTION, 2016(In Chinese).

[4] "Ministry of Environmental Protection sends 10 supervision teams to 20 provinces (cities and districts) to supervise environmental law 
enforcement and correct illegal construction,” Paper and Paper Making, vol.11, 2016(In Chinese).

[5] Yongsheng Liu and Zhejiang Huzhou Bureau of Environmental Protection, "How to deepen supervision mechanism after basic environmental law enforcement?” China Environmental News, 2015(In Chinese).
[6] Junli Tang, "Research on administrative supervision mechanism of environmental law enforcement,” Lanzhou University, May, 2015(In Chinese).

[7] Hailu Zhang and Chengxi environmental supervision team in Xiaoyi City, Shanxi Province, "How to enhance supervision mechanism after basic environmental law enforcement,” Journal of Science, 2015(In Chinese). 